\title{
Fabrication of Commercial Nanoporous Alumina by Low Voltage Anodizing
}

\author{
Ashraf K. Eessaa ${ }^{1}$, A. M. El-Shamy*2 and Y. Reda ${ }^{3}$ \\ ${ }^{1}$ Electronic Research Institute, Lap of Nanotechnology, Egypt \\ ${ }^{2}$ PhysicalChemistryDepartment, Electrochemistry and Corrosion Lab., National \\ Research Centre, El-Bohouth St. 33, Dokki, P.O. 12622, Giza, Egypt \\ ${ }^{3}$ Chemical Engineering Department, Higher Institute of Engineering and Technology \\ New Damietta, Egypt.
}

\begin{abstract}
$\mathbf{T}$ HE PRESENT work is considered as an introductory study on the procurement of membranes from nanoporous alumina through one-step anodization. The nonporous alumina was obtained by anodizing the specimens at low voltage $5 \mathrm{~V}$ for 20 minutes in phosphoric acid. The self-ordered porous arrangements can be acquired by using this process. The variables of space between pores, high pore density on the alumina surface are subjected to comparison with membranes which obtained by other methods. The mixture of phosphoric acid and chromium trioxide is used for removing the formed aluminum oxide after the first anodization. The self-ordered porous configuration is obtained at the second anodization step at the same conditions of the first anodization process. The nonporous alumina membrane was subjected to characterization of its surface morphology by scanning electron microscopy SEM and the electric properties were examined by using the electrochemical impedance test EIS. The formed nanoporous structures can be used for fabrication of sensor elements.
\end{abstract}

Keywords: Porous alumina; Anodization; Nanostructures; Nanopore; Self-organization.

\section{Introduction}

The formation of nanoporous alumina layers are important for the protection of aluminum alloys against different forms of corrosion and provide suitable surfaces for paints and adhesives applications [1-4]. The nanoporous layers can be used in nano-technologies due to the sub-micron ordered of its pores ${ }^{(5-8)}$.

The obtained nonporous alumina has widespread applications especially in fabrication of nanometer devices [9-17]. The spread applications of nonporous alumina are related to its specific and desirable properties such as large surface area, good mechanical, physical and thermal stability, biocompatible and inert [18-20].

Due to the unique properties of nonporous alumina it is highly recommended to use it in fabrication of sensors since it is found that the water molecule are could be adsorbed on the surface of the porous stricture and changes its electrical properties. The selectivity of sensor is depending on the porous layer thickness, the pore structure and diameter and its distribution and these parameters are could be controlled by the conditions of the anodizing process [21].

The properties of the obtained nonporous alumina are influenced by the conditions of the anodizing process such as; anodizing voltage and time, the temperature of the electrolyte and the concentration of the used acid $[22,23]$. The formation of self-organized growth of nonporous alumina is could be occurred by using a two steps anodization process, which allow us to obtain wellordered hexagonal arrays of nonporous alumina [24-26].

The hexagonal arrays of nonporous alumina have a whole range of applications due to easy fabrication of nanowire, nanotube, nanorods and nanodots [27-29]. The monitoring of current density increases the possibility of forming the porous structure of alumina at room temperature $[30,31]$.

This paper aims at studying the characterization and electrical properties of nonporous alumina to

*Corresponding author e-mail: elshamy10@yahoo.com 
identify the suitable application according to the obtained results.

\section{Materials and Methods}

\section{Anodizing Process}

The commercial aluminum coupons 99\% samples with a dimension of $2 \times 2 \times 0.01 \mathrm{~cm}$ was used for anodizing process. The surface irregularity and scratches of specimens were removed by mechanical cleaning with 600-1000 $\mu \mathrm{m}$ diamond paste type Meta di П-USA.

The chemical polishing approach in the pretreatment phase offering a viable, simpler, safer and faster alternative to electro polishing was applied [32]. To control the surface roughness, the samples were subjected to chemical polishing by using 1:4 mixtures of perchloric acid $\mathrm{HClO}_{4}$ and ethanol $\mathrm{C}_{2} \mathrm{H}_{5} \mathrm{OH}$ for $5 \mathrm{~min}$.

This step was followed again by rinsing with pure ethanol, and then with distilled water. The commercial aluminum samples were potentiostatically anodized at $5 \mathrm{~V}$ in phosphoric acid solutions for 20 minutes at room temperature with mechanical stirring conditions at $200 \mathrm{rpm}$.

\section{The electrochemical Techniques}

The electrochemical potentiostatic anodizing cell consisted of aluminum anode and platinum cathode immersed in phosphoric acid with concentrations $15,20,30$, and $35 \%$ by volume. The two electrodes were connected to the positive and negative poles of a 30V/6A DC-power supply type GW InstekGPC-3030DQ-Taiwan. After anodizing process, further pore adjustment was done by exposure to a chemical solution containing 5 weight percent of phosphoric acid for $30 \mathrm{~min}$ for pore opening.

\section{Scanning Electron Microscopy Measurements}

The surface morphology of anodized samples
AAO was investigated by scanning electron microscope SEM (JEOL JXA-840A) with field emission analysis facility. Pore size as well as cross section images were taken using SEM type ULTRA 55 Zeiss field emission.

\section{Electrochemical Impedance Spectroscopy}

Electrochemical impedance EIS test was conducted using Zahner Elektrik IM6 electrochemical workstation. The amplitude of the superimposed AC-signal was $10 \mathrm{mV}$ peakto-peak. The Bode plot method involves direct measurements of the impedance, $Z$, and the phase shift, $\Theta$, of the electrochemical system in the frequency range from 0.1 to $105 \mathrm{~Hz}$. All experiments have been carried out at room temperature, $25 \pm 1{ }^{\circ} \mathrm{C}$ and the potential was measured against calomel electrode in $0.1 \mathrm{M}$ $\mathrm{Na}_{2} \mathrm{SO}_{4}$ electrolyte.

The electrical resistance of AAO samples were measured by using AC-Impedance Analyzer HP4192A-LF, interfaced with computer, at frequency range $5 \mathrm{~Hz}$ to $13 \mathrm{MHz}$ and the amplitude of applied voltage: $50 \mathrm{mV}$, at room temperature. The reference electrode and the counter electrode were connected to one side of the sample, where the working electrode was connected to the other side of the sample.

\section{Results and Discussion}

Potentiodynamic Polarization Result

The polarization measurements were carried out to identify the effect of phosphoric acid concentrations on the cathodic and anodic corrosion reactions of anodized commercial aluminum. Figure 1 illustrates the obtained polarization curves of anodized commercial aluminum. The Tafel slopes and estimated polarization parameters from the polarization curves including the $E_{\text {corr }}, i_{\text {corr }}, \mathrm{b}_{\mathrm{c}}$ and $b_{a}$ are mentioned in Table 1.

TABLE 1: Potentiodynamic Corrosion data of commercial aluminum.

\begin{tabular}{|c|c|c|c|c|}
\hline Sample & $\mathbf{E}_{\text {corr }}(\mathbf{m V})$ & $\begin{array}{c}\mathbf{i}_{\text {corr }} \\
\left(\mu \mathrm{A} / \mathbf{c m}^{2}\right)\end{array}$ & Ba $\left.(\mathrm{mVdecade})^{-1}\right)$ & Bc $\left(m V\right.$ decade $\left.^{-1}\right)$ \\
\hline $35 \%$ & -614.3 & 3.4 & 154.0 & -137.0 \\
\hline $30 \%$ & -469.0 & 2.8 & 116.0 & -157.0 \\
\hline $20 \%$ & -333.4 & 1.1 & 176.0 & -176.0 \\
\hline $15 \%$ & -347.0 & 2.08 & 116.0 & -120.0 \\
\hline
\end{tabular}




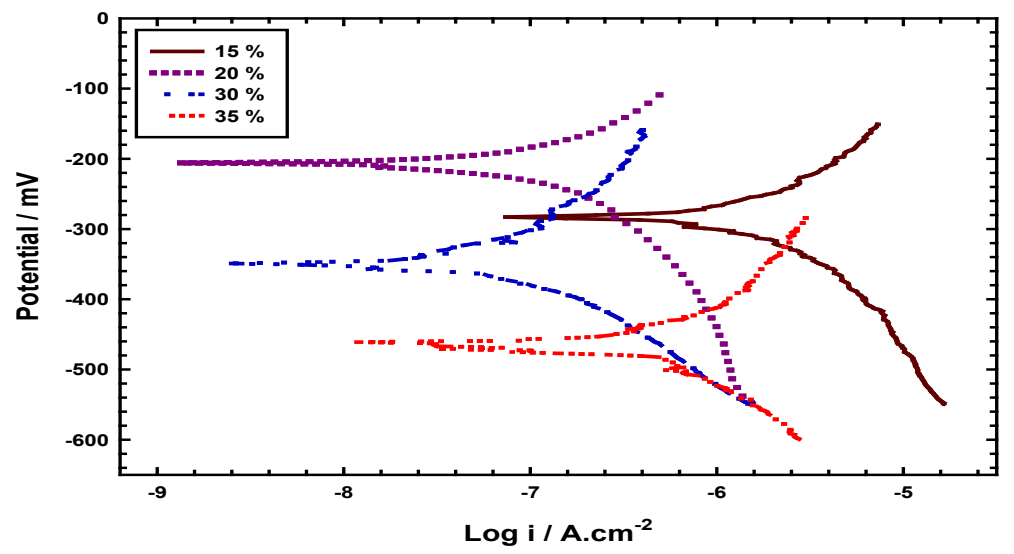

Fig. 1. The Polarization curves of anodic aluminum oxide (AAO) formed on commercial aluminum substrate. $(35 \%, 30 \%, 20 \%$ and $15 \%)$ phosphoric acid examiend in $0.1 \mathrm{M} \mathrm{Na}_{2} \mathrm{SO}_{4}$

The gathered data proved that the presence of $35 \% \mathrm{H}_{3} \mathrm{PO}_{4}$ reduced the values of cathodic and anodic current compared to the behavior of blank experiment. This behavior indicates that the phosphoric acid altered the anodic dissolution
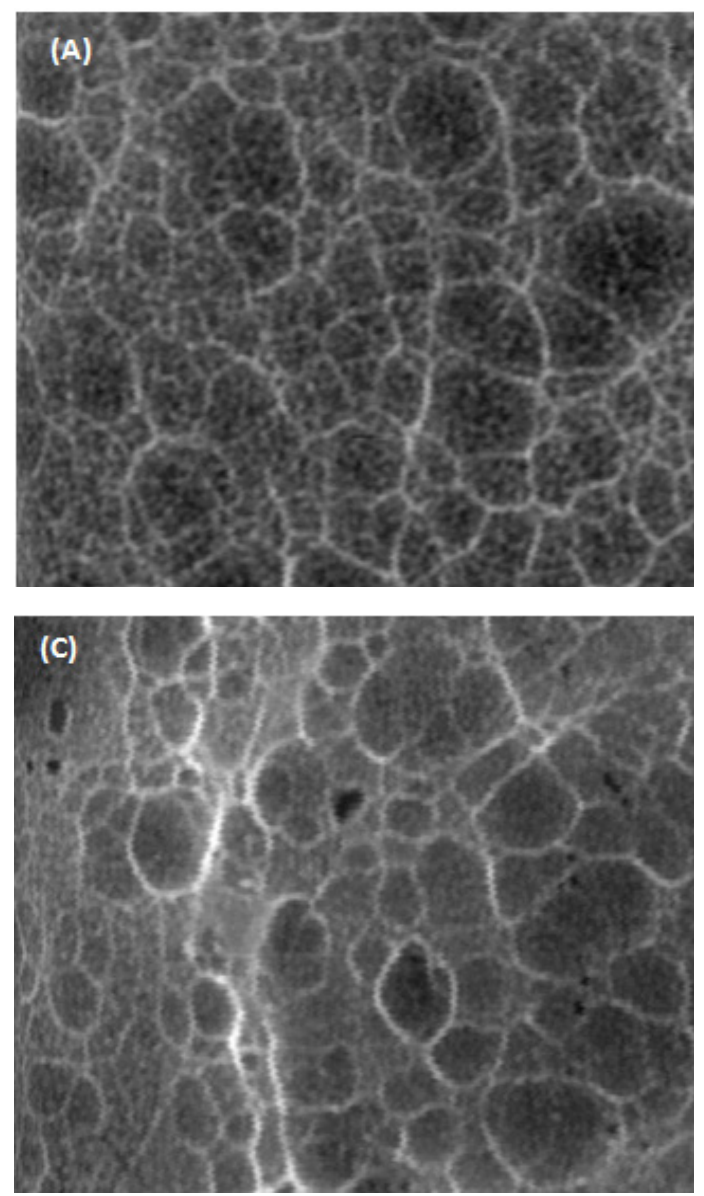

of anodized commercial aluminum and cathodic hydrogen evolution reaction processes, which increase the dissolution of the formed layer because of the existence of high concentration of hydrogen ions.
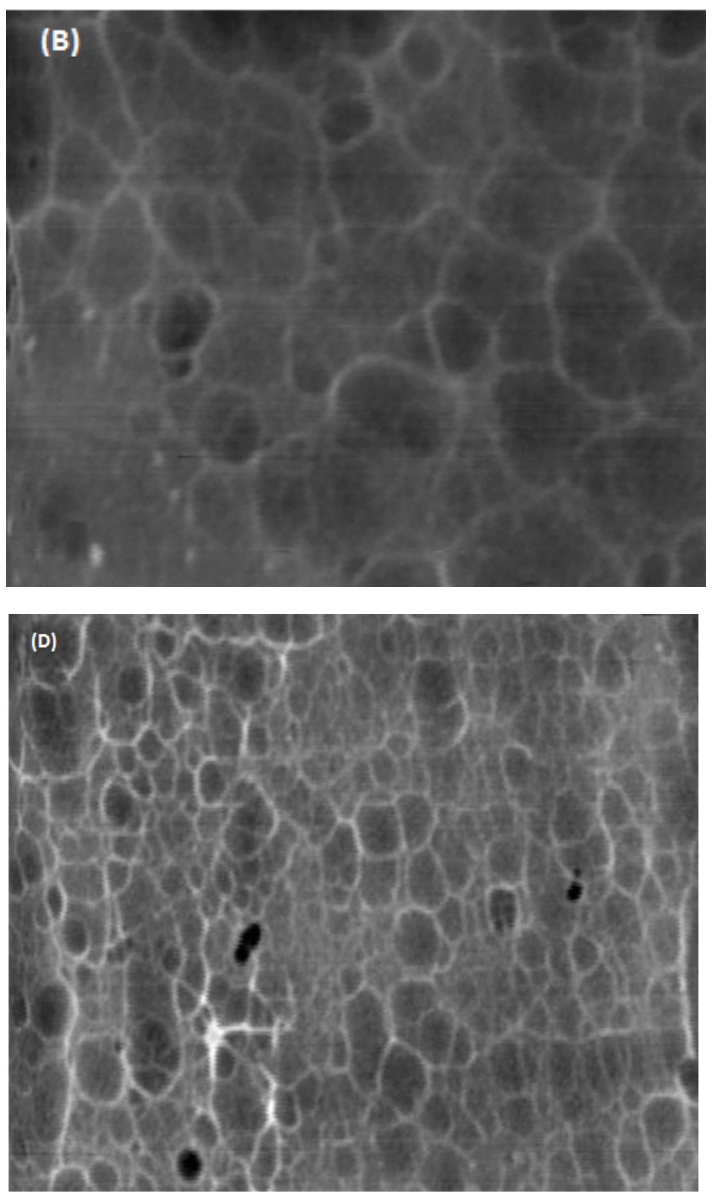

Fig. 2. SEM of anodic aluminum oxide (AAO) formed on commercial aluminum substrate at $5 \mathrm{~V}$ and 20 min at magnification of $10000 \mathrm{X}$ as a function of (a) acid concentration $35 \%$ (b) acid concentration $30 \%$ (c) acid concentration $20 \%$ (d) acid concentration $15 \%$. 
The produced hydrogen ions are easily ionizes and causes dissolution of the alumina layer. That is clearly noticed from the shift of $E_{\text {corr }}$ values towards negative direction and we can notice that the changes in polarization parameters were attributed to acid concentration.

\section{Surface Morphology}

Figure 2a-d illustrates the effect of electrolyte concentration on the surface morphology of porous anodic aluminum oxide formed on commercial aluminum substrate by using the field emission images. The specimens were applied to voltage of about $5 \mathrm{~V}$ with anodizing time of about $20 \mathrm{~min}$. The samples were tested after anodizing in $15,20,30$ and $35 \%$ by volume phosphoric acid.

Figure 2a,b shows that the typical barrier layers which detected in presence of phosphoric acid $30 \%$ as well as $35 \%$ by volume respectively. It is found that the porous oxide layer is formed at about concentration $20 \%$ by volume through the additional reduction of electrolyte and the results are presented in Figure 2c.

By lessening the concentration of the electrolyte to about $15 \%$, the barrier oxide layer is mainly formed with some pits as mentioned in Figure 2d.

The cross-section of the anodic aluminum oxide AAO, which was formed on commercial aluminum substrate in presence of $20 \%$ by volume acid medium, is illustrated in Fig. 3a. It is observed that a uniform porous structure with nearly parallel cylindrical pores of hundreds of nanometers wide, systematized in nearly hexagonal arrangement. In general, the oxide layer of aluminum covers the barrier layer, which acts as an interlayer between the porous layer and the aluminum base and the depth of the nanoporous film is greater than the barrier film.

This cell structure around the pore is collected in indiscriminately oriented crystal. The measure of the pore size, which formed on the commercial aluminum substrate, was 204-422 $\mathrm{nm}$ and the data is mentioned in Figure $3 b$.

\section{Electrochemical Impedance Spectroscopy (EIS)}

Figure 4 shows the Bode plot for anodized commercial aluminum as a function of acid concentration. The formation of a barrier layer pores by using $35 \%$ acid concentration of electrolyte was confirmed by the presence of one impedance $\mathrm{Z}$ peak, at frequency of about $200 \mathrm{~Hz}$ and phase angle $50^{\circ}$ see Figure $4 \mathrm{a}$.

Figure $4 \mathrm{a}$ represents the impedance parameters, which found to be the best fitted to Randle's model, where $\mathrm{R}_{\mathrm{s},} \mathrm{R}_{\mathrm{b}}$, and $\mathrm{C}_{\mathrm{b}}$, represent the solution resistance, barrier layer resistance and barrier layer capacitance respectively. Figure $4 \mathrm{~b}$ presents the investigational impedance results for additional concentrations. According to the fitted equivalent circuit model, the theoretical data is confirmed that the existence of a multi films structure of a barrier layer and a nanoporous film.

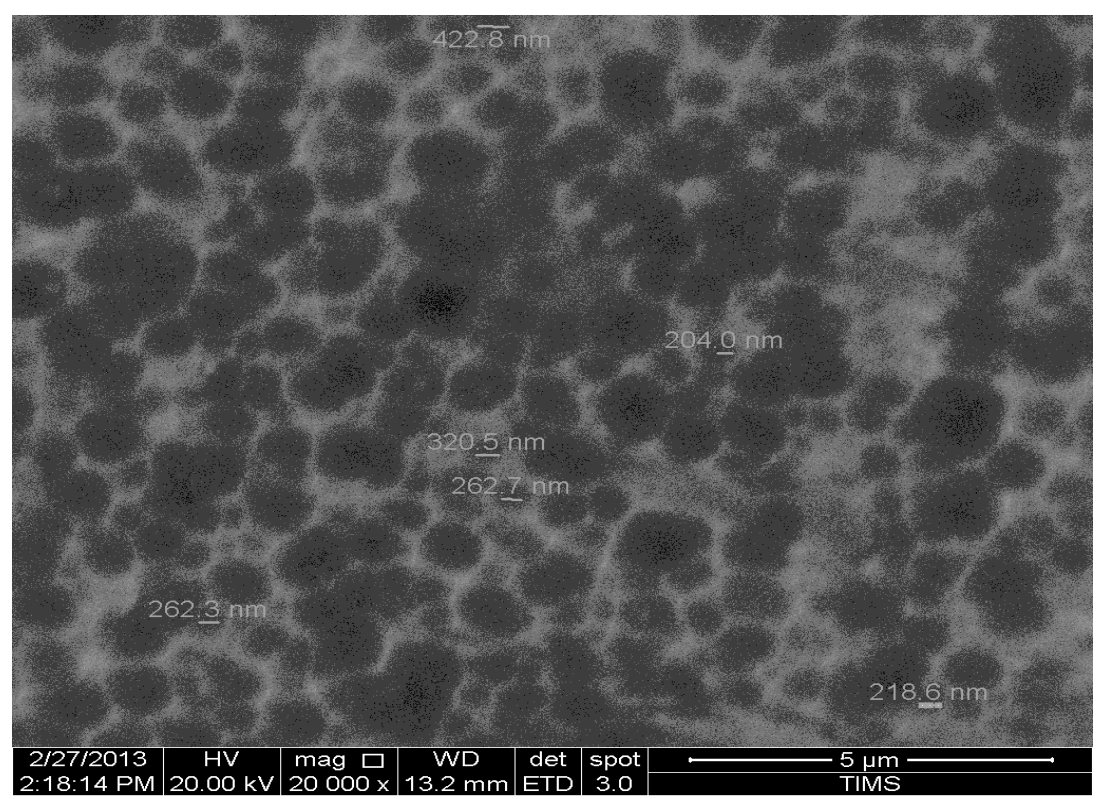

Fig. 3: SEM of anodic aluminum oxide (AAO) formed on commercial aluminum substrate, using $20 \%$ phosphoric acid (5 $\mathrm{V}$ and $20 \mathrm{~min}$ ) displays the pore size calculations.

Egypt. J. Chem. 61, No.1 (2018) 
According to this model, the impedance parameters were increased by decreasing the acid concentration. In this model, $R_{s}, R_{b}, C_{b}, R_{p}$, and $\mathrm{C}_{\mathrm{p}}$ constitute the solution resistance, barrier layer resistance, barrier layer capacitance, porous layer resistance and porous layer capacitance respectively. This could be also noticed from the peaks broadening of the impedance spectrum. From Figure 4c, it is manifest that the existence of porous layer of $\mathrm{Al}_{2} \mathrm{O}_{3}$ is conveyed by the appearance of a second phase maximum at higher frequencies, which can be ascribed to a second
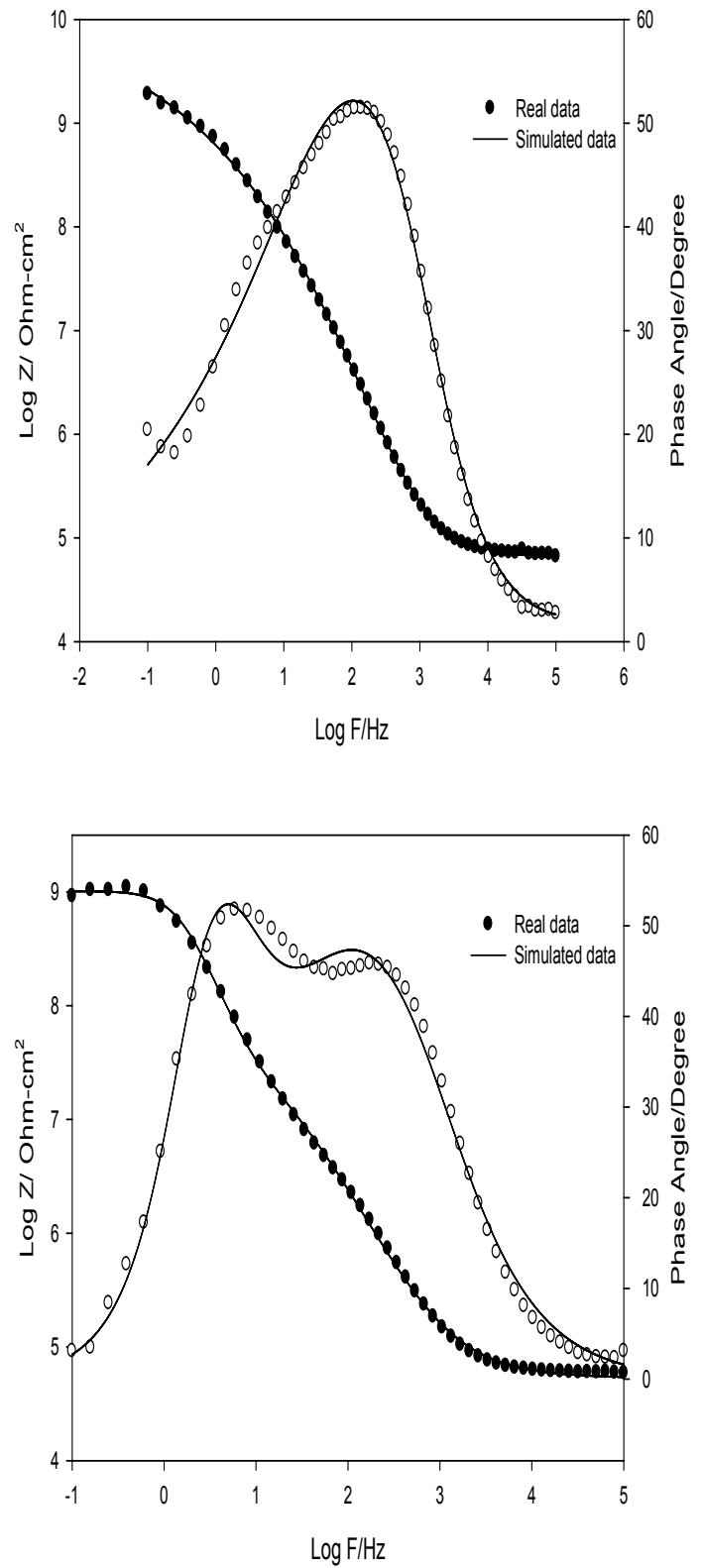

time constant, assigning a porous film formation.

This occurrence is could be observed at phase angle $60^{\circ}, 70^{\circ}$ and frequency $500 \mathrm{~Hz}, 1.5 \mathrm{~Hz}$ respectively. The considered equivalent circuit parameters are listed in Table 2 and it is could be noticed that the resistance values for the porous layer $R_{p}$ were ranged from $17.5-444.5 \mathrm{k} \Omega$. The maximum resistance value of about $444.5 \mathrm{k} \Omega$ was recorded for $20 \%$ by volume phosphoric acid, which corresponded to the formation of porous film on the commercial aluminum surface.
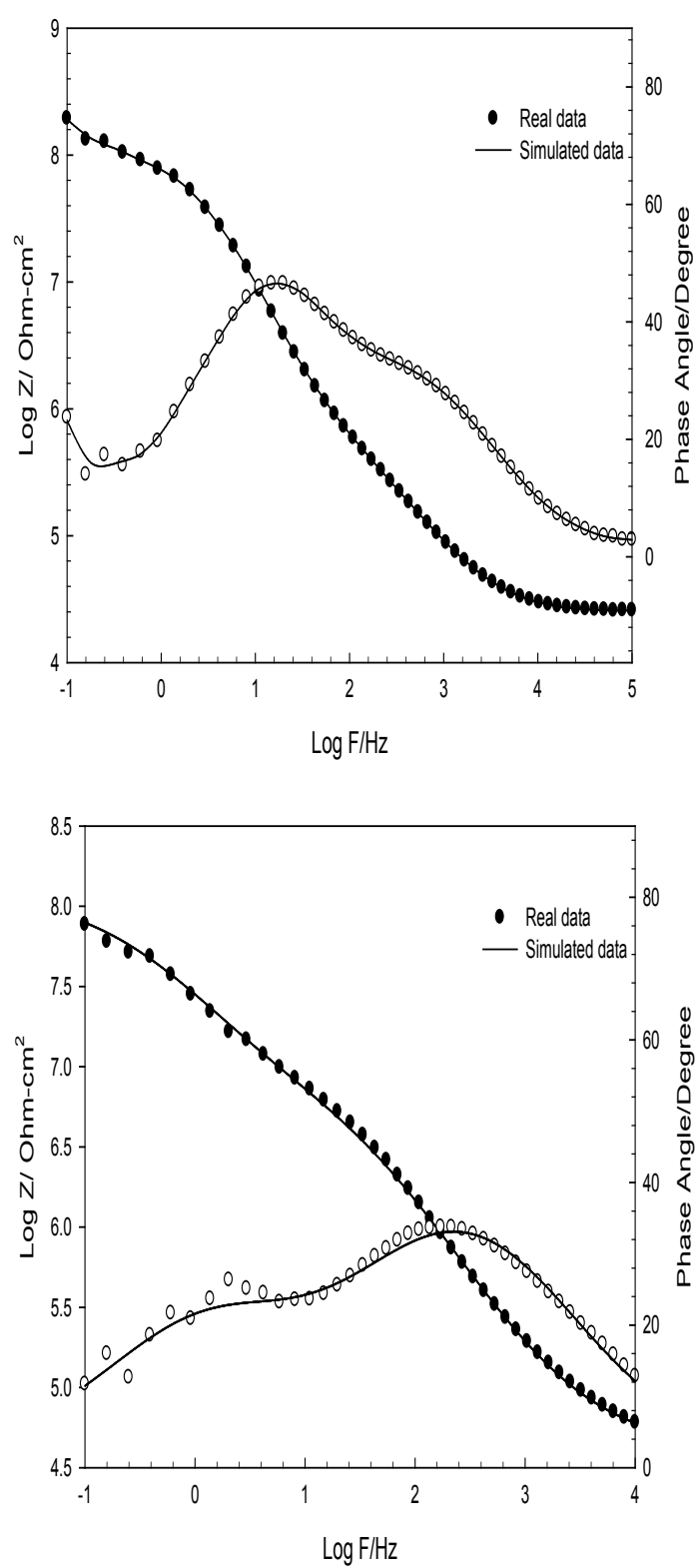

Fig. 4:Bode plots of anodic aluminum oxide (AAO) formed on commercial aluminum substrate anodizing using phosphoric acid, $5 \mathrm{~V}$ and $20 \mathrm{~min}$ (a) $35 \%$ and (b) $30 \%$ (c) $20 \%$ and (d) $15 \%$.

Egypt. J. Chem. 61, No.1(2018) 
TABLE 2: Electrochemical impedance parameters for commercial aluminum in $0.1 \mathrm{M} \mathrm{Na}_{2} \mathrm{SO}_{4}$ solution.

\begin{tabular}{|c|c|c|c|c|c|c|c|}
\hline $\begin{array}{c}\text { Concentration } \\
\text { of } \\
\text { electrolyte }\end{array}$ & $\mathbf{R}_{\mathrm{s}} / \mathbf{\Omega}$ & $\begin{array}{c}\mathrm{C}_{\mathrm{b}} / \boldsymbol{\mu F} \\
\mathbf{c m}^{-2}\end{array}$ & $\alpha_{b}$ & $\begin{array}{c}\mathrm{R}_{\mathrm{b}} / \mathrm{k} \Omega \\
\mathrm{cm}^{2}\end{array}$ & $\begin{array}{c}\mathrm{C}_{\mathrm{p}} / \mu \mathrm{F} \\
\mathbf{c m}^{-2}\end{array}$ & $\alpha_{p}$ & $\begin{array}{c}\mathrm{R}_{\mathrm{p}} / \mathrm{k} \Omega \\
\mathbf{c m}^{2}\end{array}$ \\
\hline$\% 35$ & 105.5 & 0.62 & 0.68 & 1.77 & - & - & - \\
\hline$\% 30$ & 120.4 & 0.62 & 0.74 & 3.5 & 7.1 & 0.96 & 17.5 \\
\hline$\% 20$ & 80.1 & 1.4 & 0.70 & 6.6 & 1.9 & 0.65 & 444.5 \\
\hline$\% 15$ & 125.1 & 0.48 & 0.71 & The in & $c^{7.1} Z$ & $\begin{array}{l}0.71 \\
\text { be m }\end{array}$ & $\begin{array}{c}29.9 \\
\text { ed by }\end{array}$ \\
\hline
\end{tabular}

Figure 5 displays the equivalent circuit for experimental data in case of barrier layer formation, $\mathrm{R}_{\mathrm{s}}$, solution resistance; $\mathrm{R}_{\mathrm{b}}$, barrier layer resistance; $\mathrm{C}_{\mathrm{b}}$, barrier layer capacitance as seen in figure 5a. The combined barrier and porous layer formation, $\mathrm{R}_{\mathrm{s}}$, resistance of solution; $R_{b}$, resistance of barrier layer; $C_{b}$, capacitance of barrier layer; $\mathrm{R}_{\mathrm{p}}$, resistance of porous layer and $\mathrm{C}_{\mathrm{p}}$, capacitance of porous layer is presented in figure $5 \mathrm{~b}$. The total signal loss is represented by the external and internal resistance, which seen in parallel with the capacitor for the overall signal loss. following equation (1):

$$
Z=R+j X
$$

Where $\mathrm{Z}$ is the impedance (Ohms), $\mathrm{R}$ is the resistance (Ohms) and $\mathrm{X}$ is the reactance (Ohms).

The capacitive reactance $X$ can be calculated by the following equation (2):

$$
X=-1 / w c=-1 / 2 \pi f c
$$

$C$ is the capacitance (Farads) and $f$ is the frequency (Hertz).
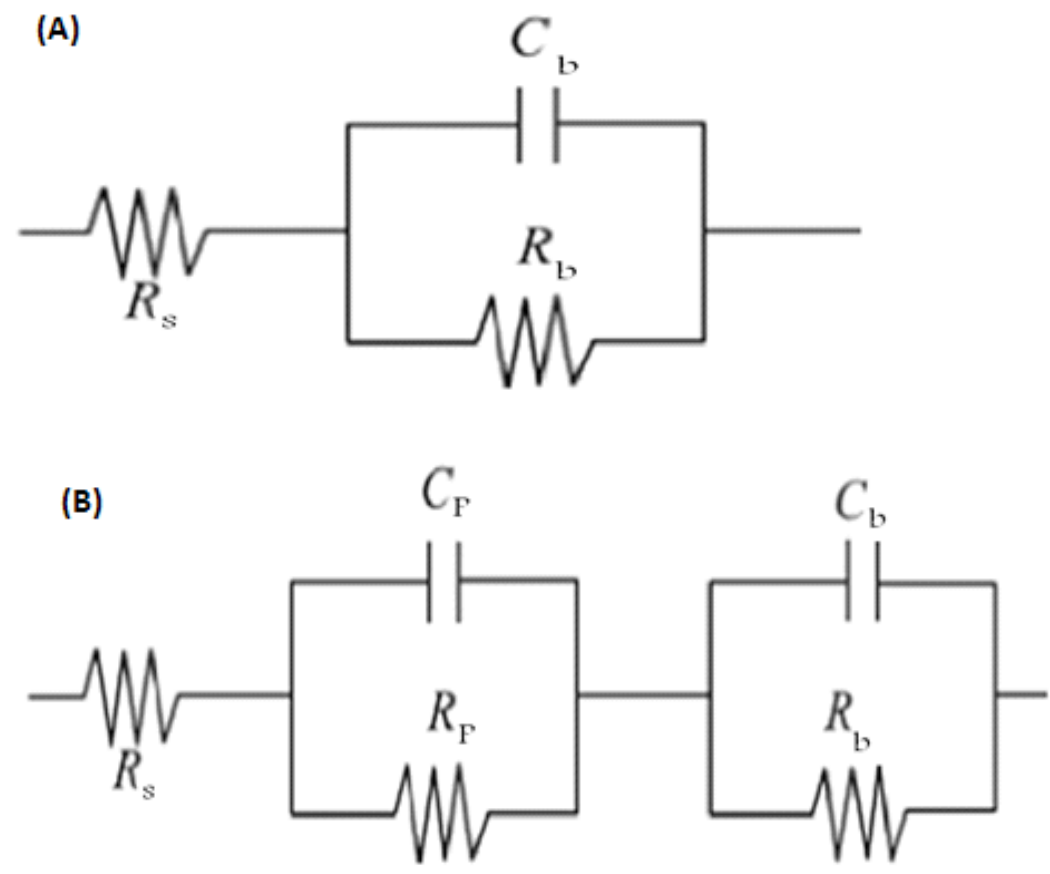

Fig. 5: Equivalent circuit model for data fitting of experimental impedance data, in case of (a) Barrier layer formation, Rs, solution resistance; $\mathrm{Rb}$, barrier layer resistance; $\mathrm{Cb}$, barrier layer capacitance (b) combined barrier and porous layer formation, $\mathrm{Rs}$, solution resistance; $\mathbf{R b}$, barrier layer resistance; $\mathbf{C b}$, barrier layer capacitance; $\mathrm{Rp}$, porous layer resistance and $\mathrm{Cp}$, porous layer capacitance. 
AC Impedance spectrum (IS)

Figure 6 illustrates the impedance spectra of the aluminum oxide AAO formed on commercial aluminum substrate anodizing using phosphoric acid, for $20 \mathrm{~min}$ at $5 \mathrm{~V}$. The highest impedance value is obtained for the anodized samples in $20 \%$ by volume phosphoric acid. This behavior reflects the formation of porous oxide structure. In addition, the lowest impedance value was observed at $35 \%$ by volume phosphoric acid due to formation of a barrier layer.

The resistance values obtained from the impedance spectrum were $10,15,100,60 \mathrm{k} \Omega$, for acid concentrations $35,30,20,15 \%$ respectively see Table 3. The nanoporous alumina was formed by anodizing of commercial aluminum specimens in phosphoric acid.

The surface characterization of the formed alumina from this electrolyte approves that the nucleation and growth of nanoporous alumina films is achievable with the support of room temperature and low voltage $5 \mathrm{~V}$.

The formed anodized aluminum oxide by this procedure is considered as an ideal for applications because of its desirable features. These characteristics include; dimensions of tunable pore, good mechanical property and good thermal stability.

The anodizing process is depending on formation of oxide layer at the anode and hydrogen evolution at the cathode. It is well known that the phosphoric acid is dissociated in water into its ions and evolution of hydrogen ion according to the following equation (3):

$$
\mathrm{H}_{3} \mathrm{PO}_{4}=\mathrm{H}_{2} \mathrm{PO}_{4}^{-}+\mathrm{H}^{+}
$$

According to presence of high concentration of hydrogen ions, the oxide film is easily ionizes and dissolves. The alumina is partially dissolute at the anode and then the porous alumina is formed see equation (4).

$$
\mathrm{Al}_{2} \mathrm{O}_{3(\mathrm{~s})}+6 \mathrm{H}_{(\mathrm{aq})}^{+}=2 \mathrm{Al}_{(\mathrm{aq})}^{3+}+3 \mathrm{H}_{2} \mathrm{O}_{(\mathrm{l})}
$$

At a given anodizing voltage, each of the current density and the coating porosity is increases with growing the temperature due to thermal enhancement of dissolution of the field assisted [18-20]. Jessensky et al show that the formed pore at room temperature is achievable and the pore diameter ranged between 80-120 $\mathrm{nm}[18]$.
There are two oxidized layers were formed the first one is concerned with the composed of commercial alumina and the second one is attributed with anion impurities such as oxide, hydroxide and phosphide, which distributed in the intermediate part [21]. The definite microstructure of anodized aluminum oxide is due to the uncommon electrical properties [21-23].

The unique characterization of morphology and porosity of oxide layer is responsible for the application of alumina-based sensors (24-28). The sensitivity of sensors are depending upon how to control many parameters such as the thickness of porous layer, pore diameter and pore diameter distribution. The conditions of the anodizing process play very important role in controlling all parameters ${ }^{(13)}$.

The formation of barrier-type layer in case of $35 \%$ by volume acid concentration is confirmed by the electrochemical impedance technique. The multi layers structure of a porous-barrier type layer are displayed in presence of other concentrations. The measured resistance values which matching with the porous layer $\mathrm{R}_{\mathrm{p}}$ were in the range of about 12.7-365.1 $\mathrm{k} \Omega$.

Generally, by decreasing the concentration of electrolyte the impedance and resistance values are increased. The highest resistance value 365.1 $\mathrm{k} \Omega$ was registered for $20 \%$ by volume phosphoric acid, corresponding to the porous film formed on the commercial aluminum surface. The electrical impedance technique is very sensitive to any polycrystalline material especially the changes in its microstructure such as the pores or any defect structure.

The obtained resistance values from the impedance technique were $10,15,100$ and $60 \mathrm{k} \Omega$, for acid concentrations 35, 30, 20and $15 \%$ respectively. The higher resistance and impedance values of anodized samples at $20 \%$ by volume were confirmed by the porous structure. In case of $35 \%$ by volume the increasing of phosphoric acid concentration causes dissolution of the porous layer and the only detectable layer is the protective barrier oxide. Meanwhile, by decreasing concentration of electrolyte down to 15 $\%$ (by volume) phosphoric acid, the impedance values decreasing as an indication that barrier layer formation (Fig.4d). The electronic or ionic conductivity is the best technique to understand the conduction mechanism of $\mathrm{Al}_{2} \mathrm{O}_{3}$ as a ceramics. 
This mechanism depends mainly on the nature of the semiconducting ceramic materials and the low sensitivity to their porous features [27]. The following equation is used to calculate the surface conductivity $\sigma$ as seen in equation (5):

$$
\sigma=\sigma_{o} \exp \left(-2 r / \delta-E_{a} / K_{B} T\right)
$$

Where $\sigma_{\mathrm{o}}$ is constant, $\mathrm{r}$ is the distance between the anionic sites and $\delta$ is the localization length.

The performance of the porous microstructure of the alumina and its ionic conductivity will be affected by the higher humidity[27]. The domination of conduction process results from the proton transmission in the thin layer of water molecules, which adsorbed and diffused into the pore sidewalls on the alumina surface. In such cases, the barrier layer will affect the sensor capacitance and it can be calculated by using the following equation (6):

$$
C=\varepsilon_{r} \varepsilon_{o} S / d_{b a r}
$$

Where $\varepsilon_{\mathrm{r}}$, and $\mathrm{d}_{\text {bar }}$ represent the relative dielectric constant and thickness of alumina barrier layer, respectively. $\mathrm{S}$ is the electrode surface area, and $\mathrm{d}$ is the dielectric layer thickness as mentioned in equation (7).

$$
1 / \mathrm{Cp} \alpha \mathrm{d}
$$

Where $\mathrm{d}$ is the thickness of barrier layer.

Finally, we can conclude that the invented nanoporous alumina by using low voltage anodizing process at room temperature have executive and specific properties necessary for many industrial applications.

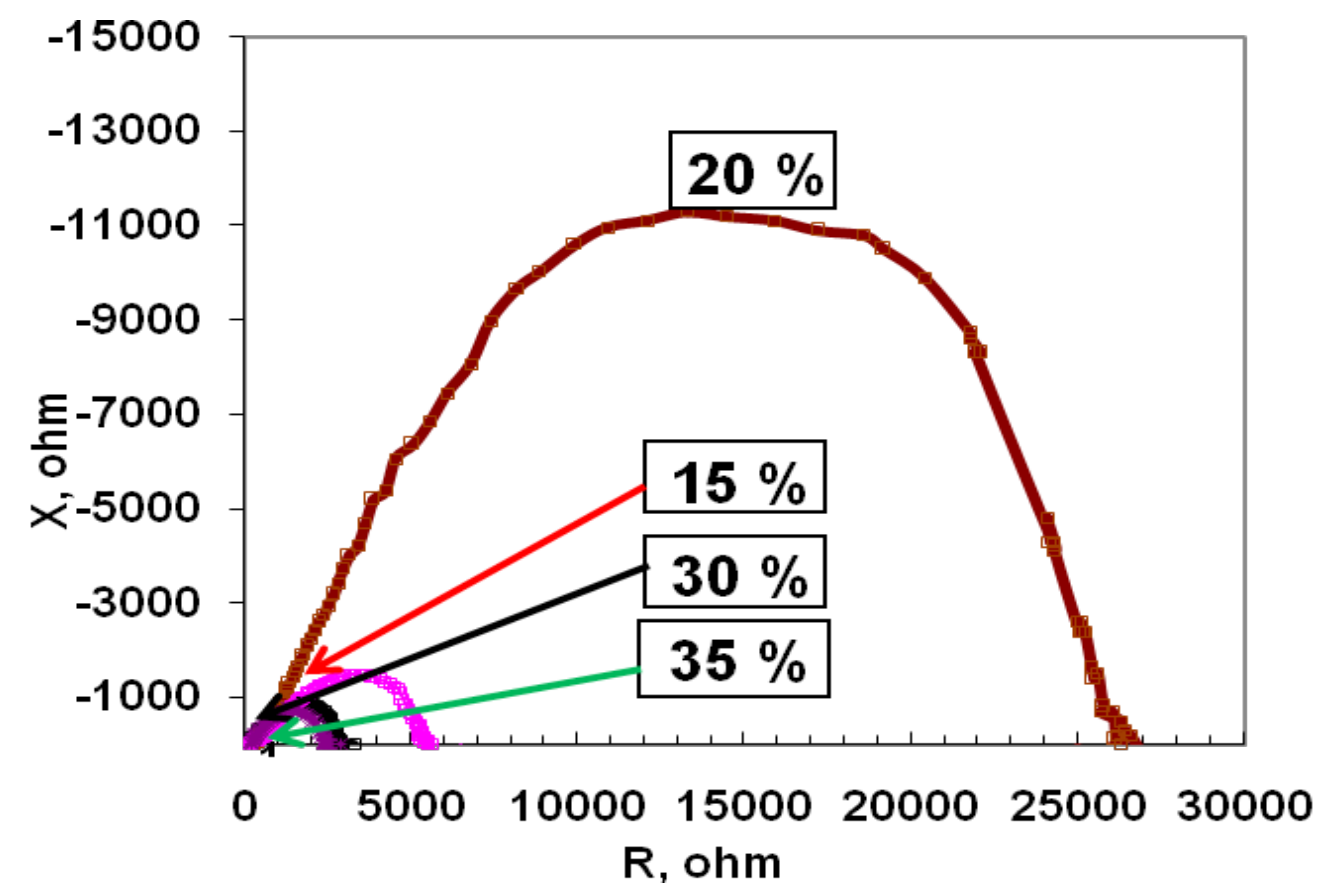

Fig. 6: Impedance spectra of anodic aluminum oxide $(A A O)$ formed on commercial aluminum substrate anodizing using $(35 \%, 30 \%, 20 \%$ and $15 \%)$ phosphoric acid (5 $\mathrm{V}$ and $20 \mathrm{~min})$.

TABLE 3: Ionic Resistance of anodic aluminum oxide $(A A O)$ formed on commercial aluminum substrate, calculated from $A C$ impedance spectra.

\begin{tabular}{cc}
\hline Concentration of electrolyte & $\mathbf{R} / \mathbf{k} \Omega$ \\
\hline $35 \%$ & 10 \\
$30 \%$ & 15 \\
$20 \%$ & 100 \\
$15 \%$ & 60 \\
\hline
\end{tabular}




\section{Conclusions}

The anodization process of commercial alumina was fruitfully achieved by using low voltage $5 \mathrm{~V}$ under one-step at room temperature. Using these conditions produce a uniform porous structure with nearly parallel cylindrical pores. The formed porous layer is of about 204-422 nanometers wide.

The depth of this nanoporous sheet was greater than the barrier layer. The creation of barrier-type layer in presence of $35 \%$ acid concentration by volume is confirmed by using the electrochemical impedance technique. The multi layers structure of a porous-barrier type layer are obtained in the other exhibited concentrations.

The electrochemical impedance techniques proved that the anodized samples in $20 \%$ by volume phosphoric acid, showed the highest resistance value $100 \mathrm{k} \Omega$, which authorizing the formation of porous structure.

\section{References}

1. F. Keller, M. S. Hunter, D. L. Robinson, Structural features of oxide coatings on aluminum $J$. Electrochem. Soc. 100, 411, (1953).

2. J. P. O’Sullivan, G. C. Wood, The morphology and mechanism of formation of porous anodic films on aluminum Proc. R. Soc. London, Ser. A 317, 511, (1970).

3. G. C. Wood, J. P. O'Sullivan, The anodizing of aluminum in sulfate solutions. Electrochim. Acta 15, 1865, (1970).

4. S. Wernick, R. Pinner, P. G. Sheasby, The Surface Treatment and Finishing of Aluminium and Its Alloys Finishing Publications Limited, Teddington, (1996).

5. H. Masuda, K. Fukada, Ordered metal nanohole arrays made by a two-stepreplication of honeycomb structures of anodic alumina. Science 268, 1466, (1995).

6. H. Masuda, H. Yamada, M. Satoh, H. Asoh, M. Nakao, T. Tamamura, Highlyordered nanochannelarray architecture in anodic alumina. Appl. Phys. Lett.71, 2770, (1997).

7. F. Li, L. Zhang, R. M. Metzger, On the growth of highly ordered pores in anodizedaluminum oxide Chem. Mater. 10, 2470, (1998).

8. K. Nielsch, J. Choi, K. Schwirn, R. B. Wehrspohn,
U. Gösele, Self-ordering regimes of porous alumina: the $10 \%$ porosity rule. Nano Lett. 2(7), 677 (2002).

9. A. Baron-Wieche'c, M. G., Burke, T. Hashimoto, H. Liu, P. Skeldon, G. E. Thompson, H. Habazaki, J. J., Ganem, I. C., Vickridge, Tracer study of pore initiation in anodic alumina formed in phosphoric acid. Electrochimica Acta 113, 302-312, (2013).

10. Yoa Masuda H., and Fukuda K., Ordered metal nanohole arrays made by a 2-step anodizing. Science 268, 1466-1468, (1995).

11. Lee W., Schwirn K., Steinhart M., Pippel E., Scholz R. and Gosele U., Structural engineering of nanoporous anodic aluminum oxide by pulse anodization of aluminum. Nat. Nanotechnology $\mathbf{3}$, 234-239, (2008).

12. Liu C. H., Yiu W. C., Au F. C. K., Ding J. X., Lee C. S., and Lee S. T., Electrical properties of zinc oxide nanowires and intermolecular p-n junctions. Appl Phys lett 83, 3168-3170, (2003).

13. Nielsch K., Müller F., Li A. P. and Gosele U., Uniform nickel deposition into ordered alumina pores by pulsed electrodeposition Adv Mater 12, 582-586, (2000).

14. Nishio K., and Masuda H., Dependence of optical properties of ordered metal whole array on refractive index of surrounding medium. Electrochem. SolidState Lett 7, H 27-28, (2004).

15. Marta Michalska-Domanska, Małgorzata Norek, Wojciech J. St, epniowski, Bogusław Budner, Fabrication of high quality anodic aluminum oxide (AAO) on lowpurity aluminum-A comparative study with the AAO produced on high purity aluminum. Electrochimica Acta 105, 424-432, (2013).

16. T. Nagaura, F., Takeuchi and S. Inoue, Fabrication and Structural Control of Anodic Alumina Films with Inverted Cone Porous Structure Using MultiStep Anodizing. Journal of Electrochimica Acta, 53, pp. 2109-2114, September, (2007).

17. Shoso Shingubara, Fabrication of Nanomaterials Using Porous Alumina Templates. Journal of Nanoparticle Research 5, pp. 17-30, March, (2003).

18. Sun-Kyu Hwang, Soo-Hwan Jeong, Hee-Young Hwang, Ok-Joo Lee and Kun-Hong Lee, Fabrication of Highly Ordered Pore Array in Anodic Aluminum Oxide. Journal of Korean Chem. Eng., 19 (3), pp. 467-473, (2002). 
19. Saha D., Mistry K. K., Giri R., Guha A., and Sensgupta K., Dependence of moisture absorption property on sol-gel process of transparent nanostructured gamma - A12O3 ceramics. Sensors and Actuators B 109,363-366, (2005).

20. Dickey E. C., Varghese O. K., Ong K. G., Gong D., Paulose M., and Grimes C. A., Room temperature ammonia and humidity sensing using highly ordered nanoporous alumina Films Sensors 2,91$110,(2002)$

21. Wang J., Wang X. H., and Wang X. D., Study on dielectric properties of humidity sensing nanometer materials Sensors and Actuators B 108 445-449, (2005).

22. Jasin'ski G, Jasin'ski P, Chachulski B Nanoporous alumina humidity sensors Metrology and measurements systems $x v(2), 195-204$, (2008).

23. Ali Eftekhari, Nanostructured Materials in Electrochemistry Wiley-VCH, Weinheim, (2008).

24. Ma Song-Jiang, Luo Peng, Zhou Hai-Hui, Fu Chao-peng and KuangYa-Fei, Preparation Of Anodic Films On 2024 Aluminum Alloy In Boric Acid-Containing Mixed Electrolyte Journal of Trans. Nonferrus Met. Soc. China, 18, pp. 825-830, (2008).

25. M. P. Proenca, C. T. Sousa, D. C. Leitao, J. Ventura, J. B. Sousa, J. P. Araujo, Nanopore formation and growth in phosphoric acid Al anodization Journal of Non-Crystalline Solids, (354), 5238-5240, (2008).

26. H. Masuda, K. Fukuda, Ordered Metal Nanohole Arrays Made by a Two-Step Replication of Honeycomb Structures of Anodic Alumina Science (268) 1466, (1995).
27. S. Z. Chu, K. Wada, S. Inoue, M. Isogai, Y. Katsuta, A. Yasumorib, Large-Scale Fabrication of Ordered Nanoporous Alumina Films with Arbitrary Pore Intervals by Critical-Potential Anodization $J$. Electrochem.Soc. 153, B384, (2006).

28. D. Navas, M. Hernández-Vélez, M. Vazquez, W. Lee, K. Nielsch, Ordered Ni nanohole arrays with engineered geometrical aspects and magnetic anisotropy. Appl. Phys. Lett. 90, 192501, (2007).

29. K. Nielsch, F. Müller, A.P. Li, U. Gösele, Uniform Nickel Deposition into Ordered Alumina Pores by Pulsed Electrodeposition. Adv. Mater. 12, 582, (2000).

30. S. J. Son, X. Bai, S. B. Lee, Drug Discov, Inorganic hollow nanoparticles and nanotubes in nanomedicine: Part 1. Drug/gene delivery applications. Today 12. 650, (2007).

31. Alaba O. Araoyinbo, M. N. Ahmad Fauzi, Srimala Sreekantan, Azizan Aziz, One-Step Anodization of Aluminum at Room Temperature Sains Malaysiana 38 (4),521-524, (2009).

32. A. O. Araoyinbo, A. F. M. Noor, S. Sreekantan and A. Aziz, Voltage effect on electrochemical anodization of aluminum at ambient temperature". International Journal of Mechanical and Materials Engineering (IJMME), Vol. 5, No. 1, 53-58, (2010).

33. Choi Y. C., Hyeon J Y, Bu S. D., Effects of anodizing voltages and corresponding current densities on self-ordering process of nanopores in porous anodic alumina anodized in Oxalic and Sulfuric Acids Journal of the Korean Physical Society 55 (2), 835 840, (2009).

(Received 28/11/2017; accepted 26/12/2017) 
تصنيع ألومينا نانوية مسامية من الألومنيوم التجاري بواسطة أنودة الجها المنخفض

اشركف كمال عبسي'، اشرف مرسى محمد الثنامى'، ياسر رضا الغزولي"

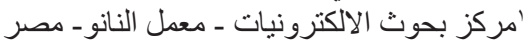

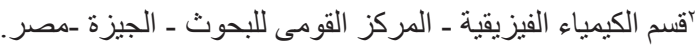

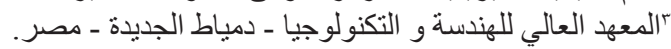

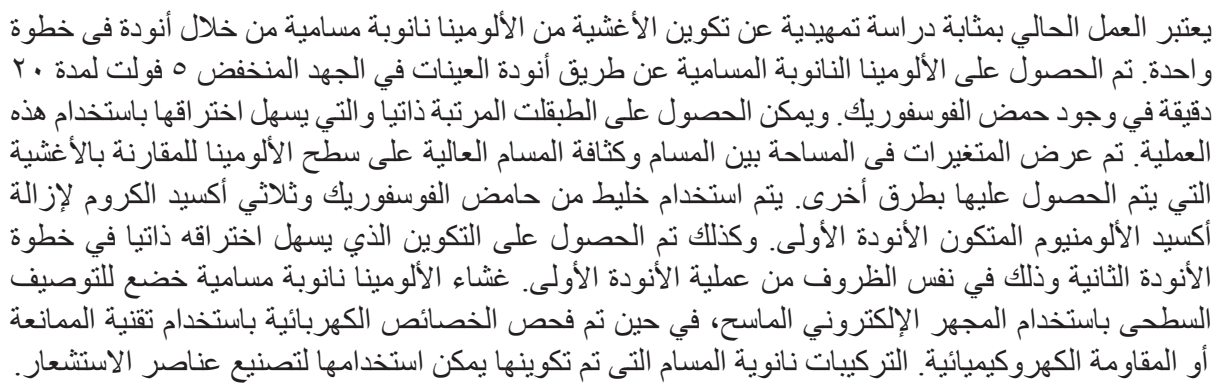

